\title{
REFLEXÃO SOBRE A PESQUISA EM ENSINO DE QUÍMICA NO BRASIL ATRAVÉS DO PANORAMA DA LINHA DE PESQUISA: LINGUAGEM E FORMAÇÃO DE CONCEITOS
}

\author{
R. O. MORAIS, T. S. SILVA, J. B. OLIVEIRA, A. B. SILVA e M. E. N. P. RIBEIRO \\ ${ }^{1}$ Instituto Federal do Rio Grande do Norte - Campus Currais Novos. \\ elenir.ribeiro@ifrn.edu.br
}

Artigo submetido em dezembro/2013 e aceito em agosto/2014

DOI: 10.15628/holos.2014.1882

\section{RESUMO}

O presente trabalho pretende apresentar um panorama nacional sobre as pesquisas em linguagem e formação de conceitos no Ensino de Química, tendo como base o Diretório de Grupos de Pesquisa no Brasil, existente no portal do CNPq. Dada a importância da linguagem e da apropriação de conceitos científicos no processo de ensino-aprendizagem dos educandos, evidenciado pelos autores que defendem a teoria construtivista, é importante que pesquisas nesta área sejam incentivadas, pois a apropriação, ou não, desses saberes por parte dos professores, tem reflexo direto na prática pedagógica e na qualidade do ensino de Química. A pesquisa realizada constatou que o número de linhas de pesquisas nesta área ainda é muito pequeno no nosso país, não chegando à proporção de 1:1 por unidade federativa, apesar do crescimento em pesquisas no Ensino de Química nos últimos anos.

PALAVRAS-CHAVE: Ensino de Química, Linguagem e Formação de Conceitos, Linhas de Pesquisa.

\section{REFLECTION ON RESEARCH IN CHEMISTRY TEACHING IN BRAZIL THROUGT THE PROFILE OF THE RESEARCH LINE: LANGUAGE AND CONCEPT FORMATION IN TEACHING CHEMISTRY}

\begin{abstract}
The present work aims to show a national overview on research in language and concept formation in Chemistry Teaching, based Directory of Research Groups in Brazil, in the portal of the CNPq. Given the importance of language and appropriation of scientific concepts in the teachinglearning process of the students, evidenced by the authors argue that the constructivist theory, it is important that research in this area should be
\end{abstract}

encouraged, as the appropriation or not such knowledge on the part of teachers have a direct impact on teaching practice and the quality of teaching chemistry. The survey found that the number of lines of research in this area is still very small in our country, not reaching the 1:1 ratio by federative unit, despite the growth in research in Chemistry Teaching in recent years.

KEYWORDS: Chemistry Learning, Language and Training Concepts, Research Areas 


\section{INTRODUÇÃO}

Segundo Vygotsky, o desenvolvimento de conceitos espontâneos e não espontâneos são partes diferentes do mesmo processo. O conceito científico e o conceito espontâneo percorrem caminhos contrários, sendo o conceito científico introduzido pelo professor, que fornece questionamentos e informações em um processo, em que o aluno, ainda em formação, de forma consciente, utiliza-o, até que o conceito torne-se familiar. O conceito espontâneo, por outro lado, está presente no cotidiano do aluno, sem que este tenha consciência a respeito de sua formação. Em ambos os casos, é necessária sua formalização, a qual se dá através da expressão verbal, durante as várias etapas de construção do conhecimento (Gerbelli et al., 2009).

Vários estudiosos se preocupam com o processo de assimilação de conceitos por parte dos alunos, e para facilitar esse processo vários modelos didático-pedagógicos foram propostos nas últimas décadas (Mortimer, 1996). Um deles é o uso de analogias para facilitar e mediar o processo de assimilação de conceitos. Porém, Lopes (1997) chama atenção para a clara confusão entre analogias e metáforas. Segundo este autor, analogias são comparações de estruturas entre dois domínios. Ou seja, deve existir uma identidade profunda entre partes das estruturas e devem tornar uma nova informação mais concreta e fácil de visualizar. As metáforas, por outro lado, são comparações nas quais sua base deve ser revelada ou mesmo criada pelo destinatário da metáfora, estas constituem-se como um dos obstáculos epistemológicos e pedagógicos para a mediação de conceitos científicos.

É importante destacar o papel da linguagem no processo de construção e assimilação de conceitos. Segundo Vygotsky, a linguagem humana possui duas funções básicas: de comunicação social e de pensamento generalizante. Em outras palavras, além de permitir a comunicação entre as pessoas ela simplifica e generaliza a experiência criando categorias conceituais, facilitando o processo de abstração (Nébias, 1999).

Posto a evidente importância da linguagem e do uso de analogias no ensino de ciências, torna-se evidente a necessidade, de se compreender como estas influenciam a formação e assimilação de novos conceitos por parte dos alunos e qual a melhor forma de utilizá-las, especialmente no ensino de ciências, ao qual geralmente os alunos apresentam maior dificuldade na aquisição de conceitos. De fato, observa-se que os alunos de modo geral, tem uma visão fragmentada e compartimentada das ciências, não conseguindo relacioná-las ao seu cotidiano, especialmente as ciências exatas, como Química e Física (Pozo e Crespo, 2009). Entretanto, observase que as pesquisas sobre linguagem e formação de conceitos relacionados ao ensino de ciências, ainda são muito tímidas, sendo praticamente nulas, se comparadas às pesquisas em outras áreas do conhecimento cientifico, inclusive no que tange ao Ensino de Química. Este trabalho pretende investigar o panorama nacional das pesquisas em Linguagem e Formação de Conceitos no Ensino de Química, tendo como parâmetro, os bancos de dados sobre a referida linha de pesquisa no Diretório de Grupos e Pesquisa no Brasil existente no sítio do Conselho Nacional de Desenvolvimento Científico e Tecnológico (CNPq), visando fornecer informações importantes desta área para licenciandos e professores de Química. 


\section{FUNDAMENTAÇÃO TEÓRICA}

\subsection{A teoria construtivista e a formação de conceitos no ensino de Química.}

O conhecimento científico é o objetivo maior do processo de ensino-aprendizagem, se dando através deste, a assimilação dos temas geradores que norteiam a prática pedagógica (Maldaner e Delizoicov, 2012). Para que o aluno possa tomar posse deste conhecimento, é preciso que a prática docente possibilite a ruptura entre as estruturas cognitivas construídas no cotidiano do estudante, dando lugar a novas estruturas, num processo que Vygotsky caracterizou como construtivista.

As ideias de Vygotsky constituem-se como uma nova perspectiva teórica no ensino de ciências por considerar que o conhecimento espontâneo e o cientifico se interinfluenciam em movimentos opostos: o primeiro em direção à abstração e o segundo para a compreensão da situação concreta (Gehlen et al., 2008, Maldaner e Delizoicov, 2012). A teoria construtivista atribui ainda um papel especial ao contexto social dos sujeitos, destacando o sujeito histórico-cultural, que interage com os objetos, mediado por estruturas linguísticas que possibilitam a generalização dos conceitos outrora adquiridos.

Por outro lado, é importante destacar que a ocorrência desta ruptura entre o conhecimento prevalente do educando e os paradigmas científicos não significa abandono (Delizoicov e Angotti, 1991, Maldaner e Delizoicov, 2012), mas sim a possibilidade de conviver com diferentes explicações para os fenômenos que constituem a vivência do educando. O discente, ao apropriar-se do conhecimento cientifico, tem a possibilidade de transitar entre esse conhecimento e o seu conhecimento prévio, caracterizado pelas suas concepções pessoais, desde que ele tenha consciência desta (Mortimer, 1996).

A abstração e a natureza microscópica, presentes nos conhecimentos químicos, provoca entre os estudantes, dificuldades na aprendizagem das diversas leis e conceitos (Costa, Passerino e Zaro, 2012). Tal situação deve-se ao fato de "a linguagem química ser essencialmente simbólica, o que pressupõe a necessidade de uma grande capacidade de abstração e generalização" (Costa, Passerino e Zaro, 2012, p.277).

Por exemplo, o conhecimento acerca das mudanças de estado físico da água é adquirido naturalmente pelos alunos na sua vida cotidiana. Este deve ser utilizado como mediador ao conceito de mudanças de estado físico da matéria, relacionando ao estado de agitação das moléculas, que é um conceito de maior embasamento cientifico. De outra forma, o conhecimento cientifico seria memorizado temporariamente pelo alunado, sem nenhum significado concreto para sua vida, e posteriormente esquecido (Bachelard, 1996; Pozo e Crespo, 2009; Rodriguez, 2013). Além disso, segundo Ramos, Silva e Lopes (2013) alguns professores possuem uma visão reduzida de ensino, limitado à escuta, à transmissão de informações, e destacam uma dicotomia entre a teoria e a prática. Ou seja, que o estudante seria livre de conhecimentos prévios e que tivesse primeiramente de impregnar-se das teorias científicas.

\subsection{A importância da linguagem para o ensino de Química.}

A adequada compreensão do processo de produção do conhecimento científico é, segundo 
Lederman (2007), uma das principais questões a serem levadas em conta quando tratamos de alfabetização científica e tem-se apresentado de forma equivocada no imaginário de estudantes e professores de diversos níveis de ensino (Rezende, Ferreira e Queiroz, 2010). Pereira (2012) observa, nos estudos de Vigotsky, Piaget e Wallon, que os três teóricos enfatizam a relação entre pensamento e linguagem, afirmando a importância desta para a construção do conhecimento significativo.

"A linguagem é então questionada na sua posição de mediadora ou construtora de uma realidade propriamente humana. Nesse contexto encontramos nos três autores em questão Piaget, Vygotsky e Wallon - o vigor de um pensamento que se realiza em direção a uma abordagem dialética das relações entre pensamento e linguagem." (Pereira, 2012, p. 278).

Os autores Trindade e Rezende (2010) apontam que a linguagem há muito deixou de ser vista como mais uma aquisição da mente humana, passando a ser vista como uma construção pautada em experiências socioculturais e históricas que possibilitam a construção de um código linguístico especifico. Através deste recurso semiótico, os indivíduos podem interagir entre si para estabelecerem significados as mais diversas modalidades de pensamento, e são estes recursos que, em certa medida, conformam a percepção de determinados objetos e eventos em um dado contexto, bem como a interpretação destes.

Para estudar e entender a Química é necessário primeiro aprender a linguagem na qual ela é descrita. Porém, existe um delicado equilíbrio entre contexto e conhecimento científico. Se por um lado, dermos ênfase ao contexto das situações envolvendo o conteúdo abordado, corremos o risco de perder o rigor exigido pela comunidade científica, se por outro, enfatizamos os conteúdos científicos, a contextualização pode ser comprometida, bem como a construção do conhecimento. Nesta perspectiva, a linguagem configura-se como mediadora, pois é através dela que os conceitos são abstraídos e generalizados (Kortland, 2007; Roque e Silva, 2008; Jiménez-Liso e De Manuel, 2009). A linguagem da Química descreve através de modelos - representados por fórmulas estruturais, equações, gráficos e figuras - as coisas do mundo como compreendidas pelo químico. Portanto, é a interação do aprendiz com uma pessoa mais experiente, que possibilita a superação do que Vigotsky chama de Zona de Desenvolvimento Proximal, permitindo assim, que este, por meio da linguagem, reconstrua ou construa novas estruturas cognitivas, através da generalização dos conceitos e significação dos diversos signos semióticos inerentes à Química. Um exemplo deste processo é justamente a utilização de analogias, que são frequentemente encontradas nos livros didáticos e materiais de apoio.

De fato, é possível observar a recorrente preocupação em como os alunos se apropriam dos conceitos científicos, e do papel da linguagem neste processo. No ensino de Química este desafio é ainda maior, por esta ser uma disciplina que apresenta problemas educacionais históricos, e por vezes se apropria de métodos tradicionalistas de ensino que pouco favorecem o processo de ensinoaprendizagem, e estruturas semióticas distantes da realidade cotidiana da maioria das pessoas.

Todos os teóricos pesquisados atestam a importância da pesquisa nesta área, posto que é através da pesquisa que os professores terão subsídios para reestruturarem suas aulas e suas metodologias e visando contribuir com essa perspectiva que este trabalho foi desenvolvido. 


\section{METODOLOGIA}

Este trabalho foi realizado mediante uma pesquisa exploratória no Diretório de Grupos de Pesquisa no Brasil no sítio do Conselho Nacional de Desenvolvimento Científico e Tecnológico (CNPq). Neste foi feito um levantamento das Instituições de Ensino Superior (IES) que possuem linhas de pesquisa voltadas para o Ensino de Química no Brasil. Foram consideradas apenas as linhas de pesquisas de ensino pertencentes à grande área de Ciências Exatas e da Terra e da área de Química. Os dados obtidos foram filtrados, considerando os objetivos de cada linha de pesquisa, como também suas palavras-chave, tema e subtemas. Posteriormente, uma nova pesquisa foi feita, considerando as linhas de pesquisa com temática referente à "linguagem e formação de conceitos", voltados para o Ensino de Química, utilizando-se da mesma metodologia para filtrar tais resultados. O censo oficial da CNPq fornece dados obtidos até o ano de 2010, e na base de dados do site do CNPq é possível encontrar os resultados de 2010 até atualidade, portanto esse trabalho deve ser considerado um panorama de pesquisas voltadas para o Ensino de Química e Linguagem e formação de conceitos, tendo que levar em consideração que os dados de 2011 a 2013 foram obtidos no sistema que sofre constante atualização. Conforme expresso na fundamentação teórica, foram desenvolvidas pesquisas bibliográficas, procurando na literatura dados que atestem a importância da utilização da linguagem e da formação de conceitos no ensino de Química, para melhor compreendermos e/ou estudarmos as causas dos problemas existentes no processo de ensinoaprendizagem e assim visualizar com propriedade os dados relativos à linha de pesquisa nessa área. Os gráficos e tabelas foram feitos mediante cálculos de percentagem, procurando destacar as regiões e/ou estados que apresentam mais linhas de pesquisas voltadas para a temática em estudo.

\section{RESULTADOS E DISCUSSÃO}

Primeiramente, é conveniente e necessário definir o termo linha de pesquisa, muita embora Borges-Andrade (2003), reforçado por Menandro (2003) relatem que há uma "frouxidão terminológica" na definição ou mesmo uma falta de definição deste termo. Por esta razão, faz-se uso da definição existente no Diretório dos Grupos de Pesquisa no Brasil, no sítio do CNPq, onde é explícito que "linha de pesquisa representa temas aglutinadores de estudos científicos que se fundamentam em tradição investigativa, de onde se originam projetos cujos resultados guardam afinidades entre si" (sítio CNPq).

Ou seja, as linhas de pesquisa relacionam trabalhos de assuntos afins que são desenvolvidos por um determinado grupo de pesquisa e embora exista essa nebulosidade frente ao termo linha de pesquisa, e por conseguinte ser possível a ocorrência de propagação de dados que podem não ser equivalentes como relata Borges-Andrade (2003), os mesmos autores relatam, e também consta no sítio do CNPq, que os dados relativos às linhas de pesquisa, que são desenvolvidos através dos grupos de pesquisa, fornecem informações que são utilizadas pela comunidade científica e tecnológica em geral e pelos comitês assessores do CNPq e CAPES como ferramenta de orientação para suas atividades, como por exemplo, explicita Menandro (2003):

"Isso fica evidente quando se percebe tratar-se de conceito largamente utilizado em curriculum vitae, em descrição de grupos de pesquisas, na especificação da abrangência de 
Programas de Pós-Graduação, em documentos oficiais de agências de fomento, destacado como elemento importante a ser considerado no âmbito da avaliação dos Programas de Pós-Graduação, que precisa ser considerado pelos formuladores de novas propostas de novos cursos de pósgraduação, mas que, ainda assim, carece de uma definição, cuja aceitação seja expressivamente compartilhada." (Menandro, 2003. p. 177).

É importante destacar que o trabalho apresenta um panorama através das linhas de pesquisa em Ensino de Química e em Linguagem e Formação de Conceito em Química, cadastradas no portal do CNPq, uma vez que havendo tais linhas de pesquisa haverá produção de dissertações, teses, trabalhos em congressos/simpósios bem como trabalhos publicados em periódicos nacionais e/ou internacionais. Todavia, o fato de haver um maior número de linhas de pesquisa não implica, necessariamente, que haverá um maior volume das referidas produções, mas fornece um indício de que tal temática está sendo estudada e de tal maneira nortear ações, conforme citado anteriormente.

Assim sendo, a pesquisa realizada no Diretório de Grupos de Pesquisa no Brasil, no portal do CNPq, forneceu um total de 107 grupos de pesquisa distribuídos nas IES de todo país. Analisandose uma a uma, foram encontradas um total de 133 linhas de pesquisa voltadas para o Ensino de Química (consultar anexo 1), distribuídas regionalmente conforme o gráfico da Figura 1.

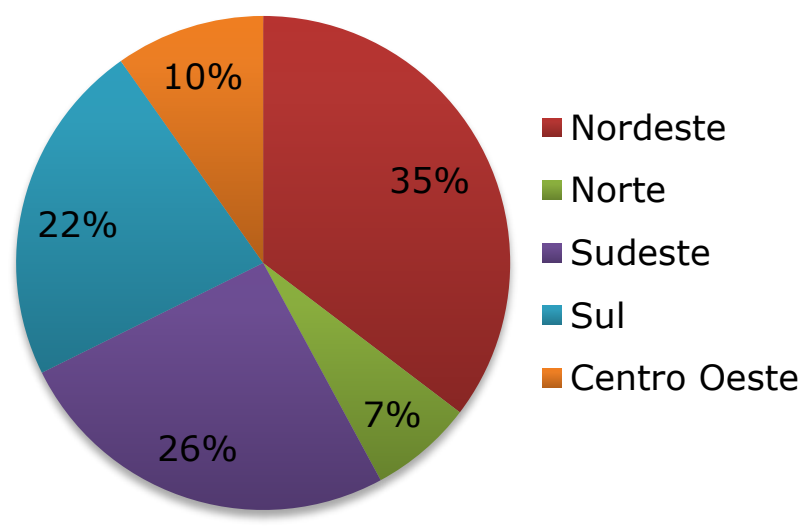

Figura 1: Gráfico, em percentagem, relativo à distribuição das linhas de pesquisa em Ensino de Química por região brasileira.

O gráfico deixa claro, que a Região Nordeste, tem posição de destaque no quadro geral da pesquisa em Ensino de Química, contando com um total de 47 linhas de pesquisa na área, embora em Sergipe não tenha linha de pesquisa na área de Ensino de Química. Esse resultado pode ser atribuído, aos recentes investimentos do governo federal, na educação e em cursos de licenciatura, principalmente por meio dos Institutos Federais, que só no Nordeste contam com 21 linhas de pesquisa em Ensino de Química, contabilizando 47\% de todas as linhas de pesquisa da região. 0 restante sendo distribuídas nas Universidades Federais e Estaduais. Esse resultado pode ser reflexo da constatada carência de professores nas áreas das ciências exatas nesta região do país.

Outro ponto importante a se destacar é que a Região Norte, que é outra região que 
notoriamente carece de professores e profissionais de educação, possui uma porcentagem ínfima nas pesquisas nesta área. Um fator que pode ser determinante nesta situação é a baixa densidade demográfica, por ser uma região de grande área territorial. Nesta região aparecem também, estados onde não foram encontradas nenhuma linha de pesquisa voltada para Ensino de Química, como: Roraima, Rondônia, Acre e Tocantins.

As Regiões Sul e Sudeste apresentam uma menor representatividade no quadro nacional, um fator que provavelmente tem influência neste resultado, é que são regiões predominantemente industriais, e com pouco déficit de professores, levando as IES da região a concentrarem suas pesquisas na área tecnológica. Tanuri (2000) disserta sobre esse fato, onde desde o fim do período imperial ocorre um "deslocamento" do eixo econômico, principalmente da região nordeste para o Sudeste, acarretando em desigualdades educacionais entre alguns estados brasileiros. Um contraponto a se destacar é o protagonismo do estado de São Paulo que possui 21 das 34 linhas de pesquisa da região, totalizando aproximadamente $62 \%$, estado que é o mais industrializado de sua região.

O gráfico a seguir (Figura 2) apresenta uma visão panorâmica das pesquisas em Ensino de Química por unidade federativa brasileira.

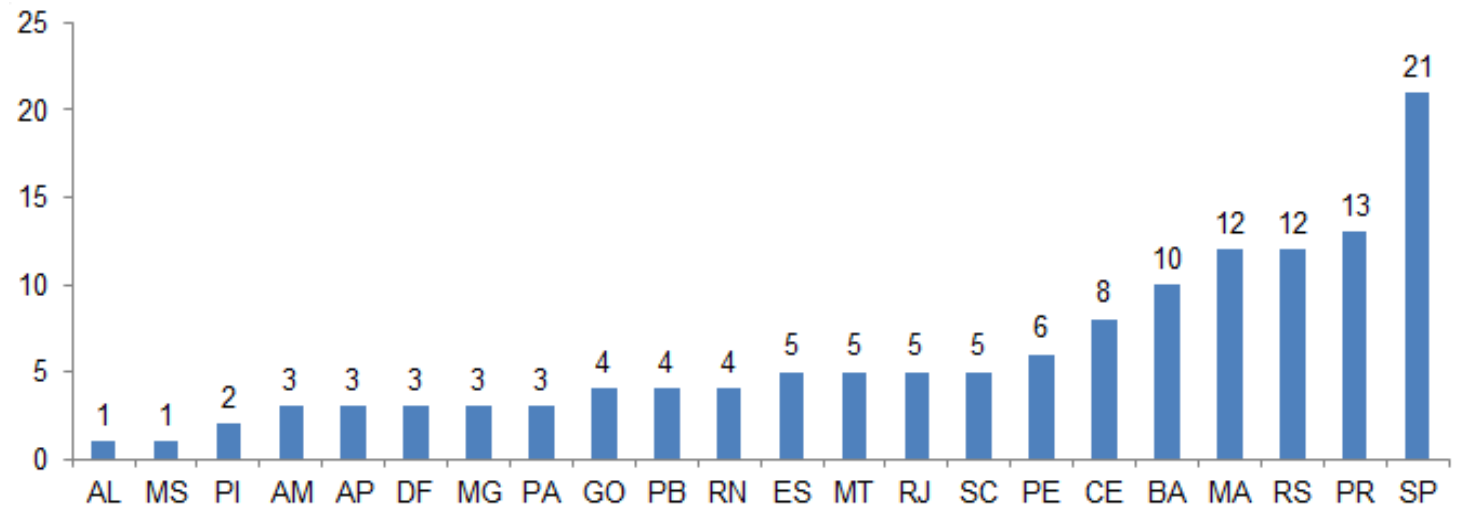

Figura 2: Gráfico, em números, relativo à distribuição das linhas de pesquisa em Ensino de Química por unidade federativa brasileira.

Também foram coletadas, as informações referentes às linhas de pesquisa a partir do banco de dados do CNPq, tomando como referência o censo de 2010. Nesse levantamento, utilizou-se o filtro "Ensino de Química", na grande área de Ciências Exatas e da Terra, relacionada à área de Química, o qual forneceu 69 resultados de linhas de pesquisas relacionadas ao Ensino de Química em geral.

Essas 69 linhas de pesquisas estão distribuídas geograficamente por todas as regiões brasileiras conforme gráfico a seguir (Figura 3). 


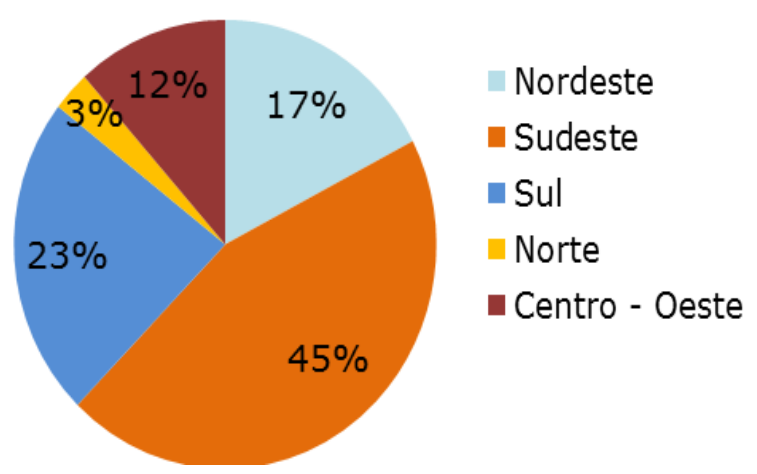

Figura 3: Gráfico, em percentagem, relativo as linhas de pesquisa relacionadas ao Ensino de Química distribuídas por região brasileira baseado nos dados do Censo 2010 - CNPq.

Observa-se um crescimento de 93\% nas pesquisas referentes ao Ensino de Química desde o censo 2010 até o ano de 2013. Novamente observamos que a Região do Nordeste se destaca, pois apresentou aproximadamente $292 \%$ de crescimento no período e sendo a que apresentou maior crescimento nessa linha de pesquisa. Como visto anteriormente, isso é resultado dos investimentos em educação, principalmente nos Institutos Federais, os quais oferecem cursos de licenciaturas, em especial licenciatura em Química e, por conseguinte, pesquisa na área de Ensino de Química.

O gráfico revela também, o baixo crescimento da região Sudeste (apenas 10\%) que como já exposto, pode ser devido ao fato de se caracterizar como região mais industrial. A região Sul contou com crescimento de $88 \%$.

Nas demais áreas é notório o crescimento de pesquisas relacionadas ao tema em estudo, como Norte (350\%), Centro-Oeste (63\%), que se mantinham acanhadas em relação a pesquisa em Ensino de Química. Vale salientar também que esse crescimento pode ter sido ocasionado por outros fatores, como por exemplo, a necessidade do ingresso de licenciados no mercado de trabalho, mercado esse, que nos últimos anos no Brasil tem sofrido graves problemas devido à falta de profissionais devidamente qualificados.

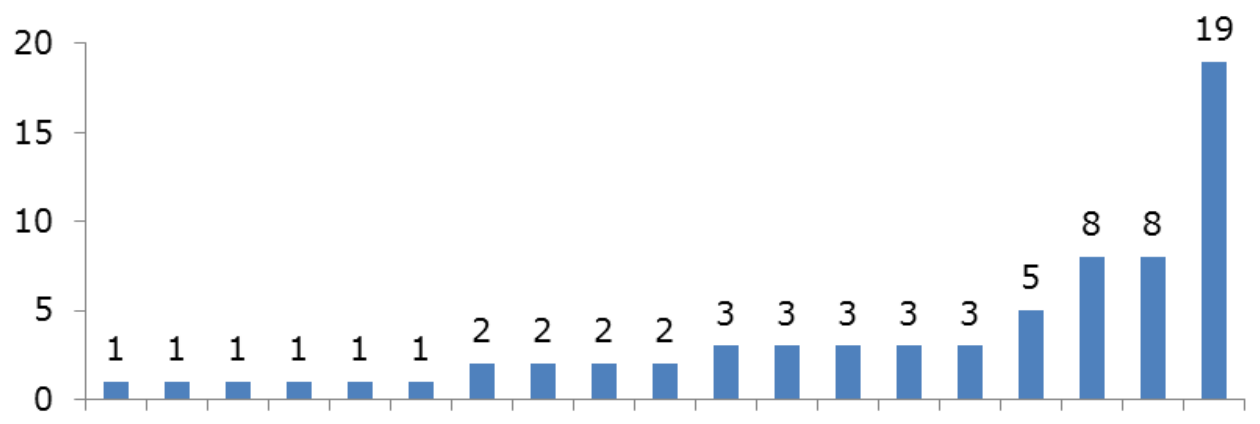

AL AM PA PB DF MS PI ES RJ RN MT MA GO CE RS SC PR MG SP

Figura 4: Gráfico, em números, relativo à distribuição das linhas de pesquisas em Ensino de Química por unidade Federativa brasileira baseado nos dados do censo de 2010 do CNPq.

Procurando ainda identificar o avanço que se obteve em nosso país com relação à linha de pesquisa "Ensino de Química", identificamos no banco de dados do portal do CNPq, o crescimento 
decorrente dos últimos 13 anos. O gráfico abaixo (Figura 5) mostra a evolução das linhas de pesquisa no período de 2000 até 2013. A quantidade de linhas de pesquisa é representada pela linha azul do gráfico, a linha vermelha representa o crescimento em porcentagem quando comparada ao ano anterior.

Observando o gráfico da Figura 5, pode-se perceber o crescimento de tal linha de pesquisa. É importante também observar o crescimento entre os anos 2010 a 2013, onde a quantidade de linhas de pesquisa cresceu 93\%, ou seja, praticamente duplicou. Como já foi exposto, esse crescimento pode estar relacionado à implantação dos cursos de licenciatura nos Institutos Federais, nos quais se desenvolve nos seus cursos de licenciatura, pesquisa na área educacional.

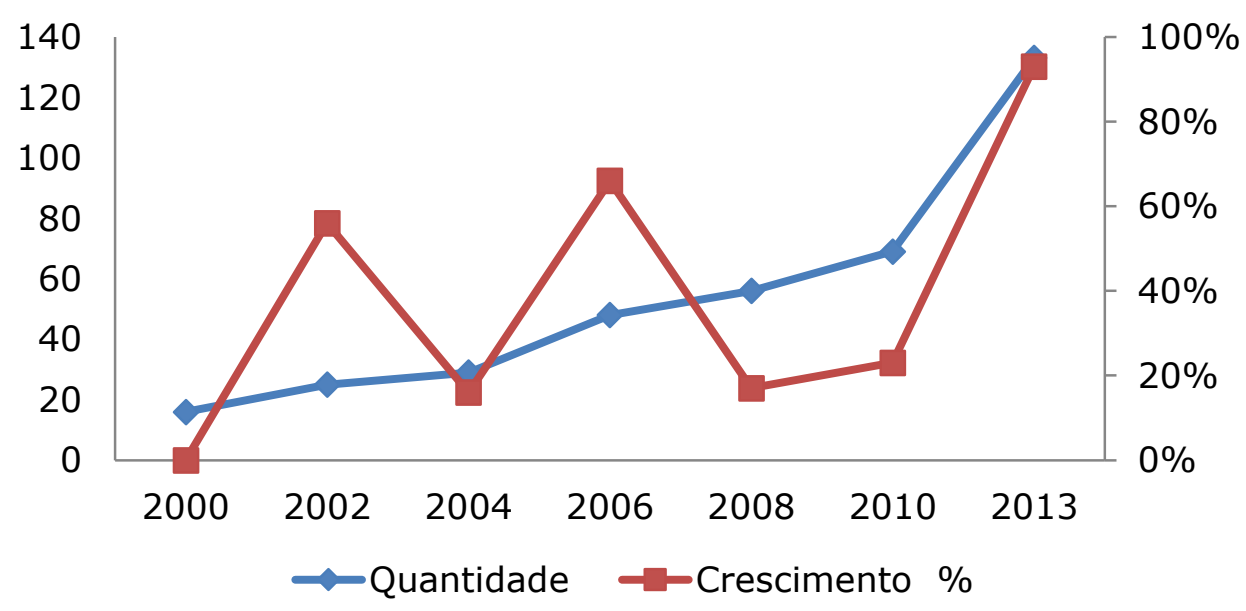

Figura 5: Gráfico relativo à evolução das linhas de pesquisa em Ensino de Química no período de 2000 a 2013 no Brasil.

Feito essa pesquisa e diante do conhecimento desse crescente número de linhas de pesquisas voltadas para o Ensino de Química, analisou-se quais dessas linhas estão relacionadas de alguma maneira com linguagem e/ou formação de conceitos para o ensino e aprendizagem de Química. A pesquisa revelou que há 16 linhas que estão distribuídas por região conforme mostra o gráfico da Figura 6 (IES que possuem essa linha constam na tabela disponibilizada no anexo 2).

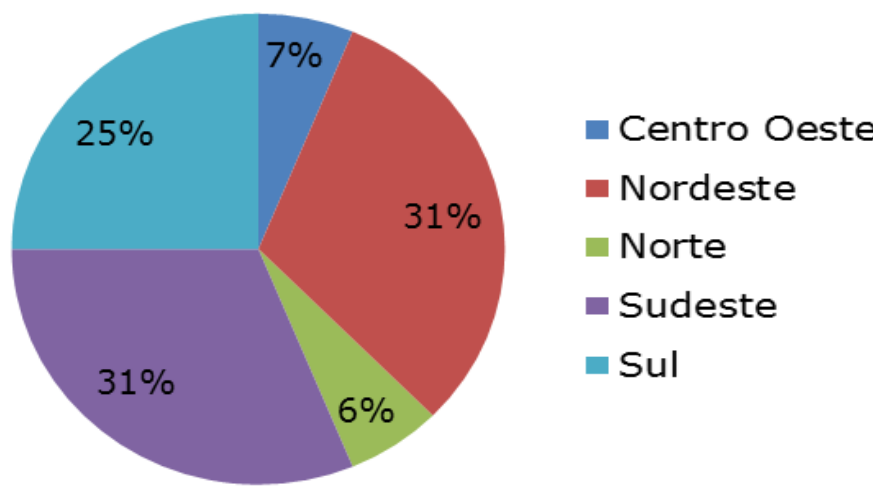

Figura 6: Gráfico, em percentagem, relativo à distribuição das linhas de pesquisa em linguagem e formação de conceitos para o Ensino de Química por unidade da Federação brasileira. 
Fazendo um comparativo entre esse gráfico (Figura 5) e o gráfico que expressa as quantidades de linhas de pesquisas voltadas para o Ensino de Química no Brasil (Figura 1), percebese uma grande semelhança. As regiões Nordeste, Sudeste e Sul novamente ganham destaque, apresentando o maior número de linhas de pesquisas voltadas para a linguagem e formação de conceitos.

A Região Nordeste, que em Ensino de Química conta com 47 linhas de pesquisa, quando se trata de linguagem e formação de conceitos, esse número cai para apenas 5 linhas de pesquisa. Destas 5 linhas de pesquisa, nenhuma delas está implantada dentro de um Instituto Federal, sendo que apenas a UESC, UECE e UFPE desenvolvem trabalho nessa linha. Enquanto que a percentagem de Institutos Federais que apresentam a linha de pesquisa em Ensino de Química corresponde a $47 \%$ de percentual total da Região Nordeste.

As regiões Sul e Sudeste somam 9 das 16 linhas de pesquisas em linguagem e formação de conceitos, e as regiões Norte e Centro-Oeste somam 2 linhas de pesquisa. Esses dados nos mostram o quanto essa linha de pesquisa ainda é tímida no sistema brasileiro de ensino. Se for considerado, por exemplo, o número de estados do Brasil, que são os 26 estados somando ainda o Distrito Federal, desse modo pode perceber que, em nosso país, a proporção de linhas de pesquisa que estudam a linguagem e a formação de conceitos para o Ensino de Química, não chega a 1 por unidade federativa.

O gráfico a seguir (Figura 7) apresenta uma visão panorâmica das pesquisas em linguagem e formação de conceitos por unidade federativa brasileira.

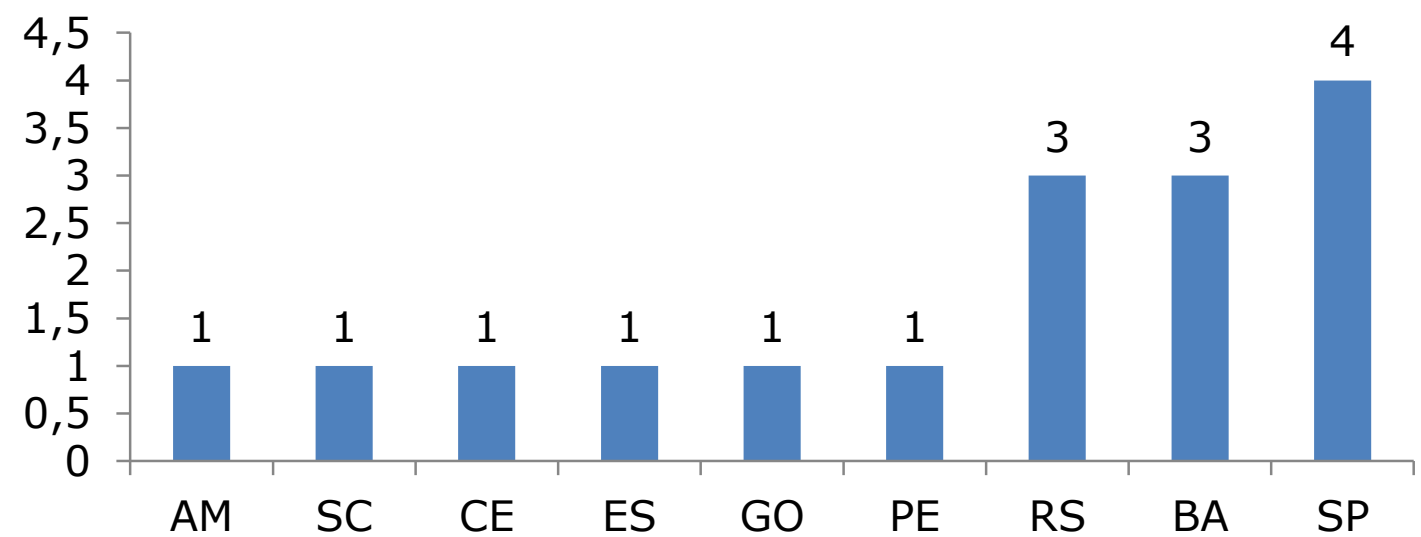

Figura 7: Gráfico, em números, relativo à distribuição das linhas de pesquisa em linguagem e formação de conceitos no Ensino de Química por unidade Federativa brasileira.

Pelo exposto, fica evidente a carência de pesquisas voltadas para linha de pesquisa em linguagem e formação de conceitos no ensino de Química no Brasil, apesar de constatado um aumento expressivo nas pesquisas em Ensino de Química no país, as pesquisas nesta área não chegam à proporção de 1:1 por unidade federativa. Esta carência tem reflexo direto na qualidade do ensino de Química, conforme afirmam Pereira e Ferreira Jr (2012), uma das maiores dificuldades dos alunos do ensino médio na disciplina Química nas provas do ENEM (Exame Nacional do Ensino Médio) é a compreensão da linguagem por trás das questões, que na maioria das vezes exige muito mais do que um conhecimento teórico da disciplina e do conteúdo programático do componente 
curricular, e sim uma série de estruturas cognitivas que devem ser elaboradas e trabalhadas durante toda a vida acadêmica. Porém, para que essa dificuldade seja superada, é preciso que o professor compreenda todas as implicações de sua prática pedagógica, e estabeleça esta ligação entre a linguagem e o conhecimento próprios do aluno, com a linguagem e o conhecimento específicos do campo de estudo cientifico, e isso só é possível através de pesquisa. Novos grupos de pesquisa que atuem nesta linha de pesquisa podem e devem ser incentivados para a construção de novos conhecimentos acerca do processo de formação de conceitos químicos por parte dos estudantes, produzindo assim novos materiais que possam subsidiar a prática pedagógica e proporcionar a mudança de paradigmas que o ensino de Química no país necessita.

\section{CONCLUSÃO}

Conclui-se através dos dados levantados, considerando as linhas de pesquisa cadastradas no CNPq, que as pesquisas em Ensino de Química no país têm tido um crescimento acelerado nos últimos anos, mas o número relativo de linhas de pesquisa ainda é pequeno devido a grande extensão do nosso país. As regiões do Nordeste, Sul e Sudeste são as que apresentam o maior número de linhas de pesquisa, e entre elas o Nordeste é a que apresenta a maior taxa de crescimento nas pesquisas nesta área, o aumento no número de linhas de pesquisa em ensino de Química na região foi próximo de 292\% entre 2010 e 2013, esse fato que se deve principalmente a inserção dos cursos de licenciatura nos Institutos Federais. A pesquisa apontou também que de todas as linhas de pesquisa voltadas para Ensino de Química, apenas 16 estão relacionadas com linguagem e formação de conceito, novamente com destaques para as regiões Nordeste, Sul e Sudeste.

Dada à importância de se compreender o processo de formação de conceitos científicos, e do papel que a linguagem tem sobre este, evidencia-se a necessidade de se buscar novas teorias e métodos que venham a favorecer esses aspectos dentro da pratica pedagógica. No ensino de Química esses estudos ganham ainda mais importância devido ao alto grau de abstração inerente da linguagem própria e dos objetos de estudo da Química. Porém, a presente pesquisa constatou que apesar das pesquisas em ensino de Química no país terem crescido vertiginosamente nos últimos anos, o número de linhas de pesquisa nesta área ainda é muito pequeno dada às proporções do nosso país, e as dificuldades educacionais enfrentadas principalmente no ensino de ciências. Dentro destas linhas de pesquisa, observamos também que as pesquisas em linguagem e formação de conceito ainda ocupam um papel de coadjuvante, sendo apenas 16 em todo país. Desta forma, torna-se necessário que que as IES, os professores, e as agências de fomento, virem suas atenções para esse quadro, considerado preocupante, pois este tem reflexo direto na qualidade do ensino de Química que está sendo oferecido para nossos estudantes.

\section{AGRADECIMENTOS}

PROPI-IFRN, COPEIN-IFRN/CN, PIBID/CAPES

\section{REFERÊNCIAS BIBLIOGRÁFICAS}

1. BACHELARD, G. TRADUAÇÃO: ABREU, E.S. A formação do espírito científico: contribuição para 
uma psicanalise do conhecimento. Rio de Janeiro: Contraponto. 1996. Em: http://bvespirita.com/A\%20Forma\%C3\%A7\%C3\%A3o\%20do\%20Esp\%C3\%ADrito\%20Cient\%C3 \%ADfico\%20(Gaston\%20Bachelard).pdf

2. BORGES-ANDRADE, J. E. Em Busca do Conceito de Linha de Pesquisa. Revista de Administração $\begin{array}{lllll}\text { Contemporânea, } & \text { v.7, } & \text { n.2, } & \text { p.157-170. }\end{array}$ http://www.scielo.br/pdf/rac/v7n2/v7n2a09.pdf

3. CNPq. Censo. Busca de linhas de pesquisa. Out. 2013. Em: http://dgp.cnpq.br/buscagrupo/

4. CNPq. Diretório dos Grupos de Pesquisa no Brasil. Out. 2013. Em: http://dgp.cnpq.br/buscaoperacional/

5. CNPq. Perguntas frequentes. Diretório dos Grupos de Pesquisa no Brasil. Out. 2013. Em: http://dgp.cnpq.br/diretorioc/index.html

6. COSTA, R.G., PASSERINO, L.M. e ZARO, M.A. Fundamentos teóricos do processo de formação de conceitos e suas implicações para o ensino e aprendizagem de Química. Ensaio Pesquisa em Educação em Ciências, v.14, n.1, p.271-281. 2012. Em: http://www.redalyc.org/articulo.oa?id=129523627018

7. DELIZOICOV, D. e ANGOTTI, J.A. Física, Coleção Magistério - 2o Grau, São Paulo: Cortez. 1991.

8. GEHLEN, S.T., AUTH, M.A., AULER, D., MALDANER, O.A. e PANSERA-DE-ARAÚJO, M.C. Freire e Vigotski no contexto da educação em Ciências: aproximações e distanciamentos. Ensaio Pesquisa em Educação em Ciências, v.10, n.2, p.267-282.2008. Em: http://www.portal.fae.ufmg.br/seer/index.php/ensaio/article/view/150/212

9. GERBELLI, B.B., CARDOSO, J.G., SILVA, J.C.A., MERCÚRIO, M.E., RODRIGUES, M.B..S.G., POJAR, R., POSTAL, T. D. e HENRIQUES, V.B. Formação de professores e formação de conceitos científicos segundo Vigorski. XVIII Simpósio Nacional do Ensino de Física. 2009. Em: http://www.cienciamao.usp.br/dados/snef/_formacaodeprofessoresefo.trabalho.pdf

10. GÓES, M.C.R. e CRUZ, M.N. Sentido, significado e conceito: notas sobre as contribuições de Lev Vigotski. Pro-Posições, v.17, n.2(50), p.31-45. 2006. Em: http://www.proposicoes.fe.unicamp.br/ proposicoes/textos/50_dossie_goes_mcr_etal.pdf

11. JIMÉNEZ-LISO, M.R. e DE MANUEL, E. La Química cotidiana, una oportunidad para el desarrollo profesional del profesorado. Revista Electrónica de Enseñanza de las Ciencias, v.8, n.3, p.878900. 2009. Em: http://reec.uvigo.es/volumenes/volumen8/ART7_Vol8_N3.pdf

12. KORTLAND, J. Context-based science curricula: Exploring the didactical friction between context and science content. 10 European Science Education Research Association. 2007. Em: http://www.staff.science.uu.nl/ kortl101/art_esera-07-synopsis.pdf

13. LEDERMAN, N.G. Nature of science: Past, present, and future. Handbook of research on science education, p. 831-879. 2007.

14. LOPES, A.R.C. Conhecimento escolar em Química: processo de mediação didática da Ciência. Química Nova, v.20, n.5, p.563-568. 1997.

15. MACENO, N.G. e GUIMARÃES, O.M. Concepções de ensino e de avaliação de professores de Química do Ensino Médio. Revista Electrónica de Enseñanza de las Ciencias, v.12, n.1, p.24-44. 2013. Em: http://reec.uvigo.es/volumenes/volumen12/REEC_12_1_2_ex648.pdf 
16. MALDANER, S.T.G.O.A. e DELIZOICOV, D. Momentos pedagógicos e as etapas da Situação de Estudo: complementaridades e contribuições para a Educação em Ciências. Ciência \& Educação, v.18, n.1, p.1-22. 2012. Em: http://www.scielo.br/pdf/ciedu/v18n1/01.pdf

17. MASSI, L., DE ABREU, L.N. e QUEIROZ, S.L. Apropriação da linguagem científica por alunos de iniciação científica em Química: considerações a partir da produção de enunciados científicos. Revista Electrónica de Enseñanza de las Ciencias, v. 7, n.3, p.704-721. 2008. Em: http://reec.uvigo.es/volumenes/volumen7/ART11_Vol7_N3.pdf

18. MENANDRO, P.R.M. Linha de Pesquisa: Possibilidades de Definição e Tipos de Utilização do Conceito. Revista de Administração Contemporânea, v.7, n.2, p.177-188. 2003. Em: http://www.scielo.br/pdf/rac/v7n2/v7n2a09.pdf

19. MORTIMER, E.F. Construtivismo, mudança conceitual e ensino de ciências: para onde vamos. Investigações em Ensino de Ciências, v.1, n.1, p.20-39. 1996. Em: http://www.if.ufrgs.br/ienci/artigos/Artigo_ID8/v1_n1_a2.pdf

20. NÉBIAS, C. Formação dos conceitos científicos e práticas pedagógicas. Interface - Comunicação, Saúde, Educação, v.3, n.4, p.133-140. 1999. Em: http://www.scielo.br/pdf/icse/v3n4/11.pdf

21. PEREIRA, C.L. Piaget, Vygotsky and Wallon: contributions for language studies. Psicologia em Estudo, v.17, n.2, p.277-286. 2012. Em: http://www.scielo.br/pdf/pe/v17n2/v17n2a10.pdf

22. PEREIRA, L.F. e FERREIRA JR., T.M. A utilização de estratégias de leitura na interpretação das questões de Química do ENEM. in: VII CONNEPI. 2012. Em: http://propi.ifto.edu.br/ocs/index.php/connepi/vii/paper/view/2576/1257

23. POZO, J.I. e CRESPO, M.A.G. A Aprendizagem e o Ensino de Ciências: Do conhecimento cotidiano ao conhecimento científico. Porto Alegre: Artmed. 2009.

24. PREDEBON, F. Evolução das concepções didáticas de futuros professores de Química sob uma perspectiva investigativa construtivista. Dissertação. Porto Alegre: ISBS/UFRGS. 2009. Em: http://www.lume.ufrgs.br/bitstream/handle/10183/16337/000702367.pdf?sequence=1

25. PYBURN, D., PAZICNI, S., BENASSI, V. e TAPPIN, E.E. Assessing the relation between language comprehension and performance in general chemistry. Chemistry Education Research and

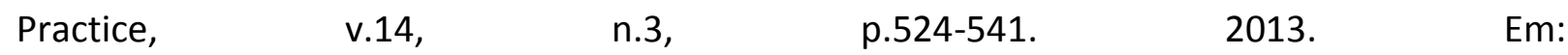
http://www.rsc.org/suppdata/rp/c3/c3rp00014a/c3rp00014a.pdf

26. QUEIROZ, S.L. A linguagem escrita nos cursos de graduação em Química. Química Nova, v.24, n.1, p.143-146. 2001. Em: http://www.scielo.br/pdf/qn/v24n1/4463.pdf

27. RAMOS, R.C., SILVA, H.S. e LOPES, J. A aprendizagem no ensino-aprendizagem das Ciências Naturais através de um método de aprendizagem cooperativa. Revista Electrónica de Enseñanza de las Ciencias, v.12, n.2, p.334-346. 2013. Em: http://reec.uvigo.es/volumenes/volumen12/reec_12_2_6_ex406.pdf

28. REIS, M. Química: Meio Ambiente, Cidadania, Tecnologia. São Paulo: FTD. 2010

29. REZENDE, F.S., FERREIRA, L.N.A. e QUEIROZ, S.L. Concepções a respeito da construção do conhecimento científico: uma análise a partir de textos produzidos por estudantes de um curso superior de química. Revista Electrónica de Enseñanza de las Ciencias, v.9, n.3, p.596-617. 2010. Em: http://reec.uvigo.es/volumenes/volumen9/ART6_Vol9_N3.pdf

30. RIGOLON, R.G. e OBARA, A.T. Distinção entre analogia e metáfora para aplicação do modelo 
Teaching with analogies por licenciandos de Biologia. Revista Electrónica de Enseñanza de las Ciencias, v.10, n.3, p.481-498. $2011 . \quad$ Em: http://reec.uvigo.es/volumenes/volumen10/REEC_10_3_5.pdf

31. RODRIGUEZ, M. Language problems in chemistry learning. 5th International Conference on Education and New Learning Technologies. $2013 . \quad$ Em: http://library.iated.org/view/RODRIGUEZ2013LAN

32. ROQUE, N.F. e SILVA, J.L.P.B. A Linguagem Química eo ensino da Química Orgânica. Química $\begin{array}{lllll}\text { Nova, } & \text { v.31, } & \text { p.921-923. } & 2008 . & \text { Em: }\end{array}$ http://quimicanova.sbq.org.br/qn/qnol/2008/vol31n4/33-ED08026.pdf

33. SCHNETZLER, R.P. A pesquisa em Ensino de Química no Brasil: Conquistas e Perspectivas. Química Nova, v.25, supl.1, p.14-24. 2002. Em: http://www.scielo.br/pdf/qn/v25s1/9408.pdf

34. SILVA, J.C. e SILVA, A.d.C.T. Pressupostos da teoria semiótica de Peirce e sua aplicação na análise das representações em química. VI Colóquio Internacional Educação e Contemporaneidade. 2012. Em: https://ri.ufs.br/bitstream/123456789/683/1/PressupostosSemioticaPeirce.pdf

35. SOUZA, V.A. e JUSTI, R.S. Interlocuções possíveis entre linguagem e apropriação de conceitos científicos na perspectiva de uma estratégia de modelagem para a energia envolvidas nas Transformações Químicas. Ensaio Pesquisa em Educação em Ciências, v.13, n.2, p. 31-46. 2011. Em: http://www.portal.fae.ufmg.br/seer/index.php/ensaio/article/view/310/610

36. STEFAN, H. Vygotsky e o conexionismo na formação de conceitos. Letras de Hoje-Estudos e debates de assuntos de linguística, literatura e língua portuguesa, v.36, n.3, p.417-424. 2013. Em: http://revistaseletronicas.pucrs.br/ojs/index.php/fale/article/view/14596/9755

37. TANURI, L.M. Historia da Formação de Professores. Revista Brasileira de Educação, v.14, n.2, p.61-88. 2000.

Em: http://www.anped.org.br/rbe/rbedigital/rbde14/rbde14_06_leonor_maria_tanuri.pdf

38. TRINDADE, M. e REZENDE, F. Novas perspectivas para a abordagem sociocultural na educação em ciências: os aportes teóricos de John Dewey e de Ludwig Wittgenstein. Revista Electrónica de Enseñanza de las Ciencias, v.9, n.3, p.487-504. 2010. Em: http://reec.uvigo.es/volumenes/volumen9/ART1_Vol9_N3.pdf

\section{ANEXOS}

Anexo 1 - Linhas de pesquisa em Ensino de Química, atualizações entre 2010 e 2013 no site do CNPq.

\begin{tabular}{|c|c|c|c|c|}
\hline Linha de Pesquisa & IES & $\begin{array}{c}\text { Ultima } \\
\text { Atualização }\end{array}$ & UF & Região \\
\hline $\begin{array}{l}\text { Desenvolvimento de conteúdos de Química } \\
\text { com experimentação demonstrativa }\end{array}$ & UFMT & $\mathrm{dez} / 12$ & MT & $\begin{array}{l}\text { Centro- } \\
\text { Oeste }\end{array}$ \\
\hline Ensino de Química & UFMT & $\mathrm{dez} / 12$ & MT & $\begin{array}{l}\text { Centro } \\
\text { Oeste }\end{array}$ \\
\hline Tabela periódica virtual & UFMT & $\mathrm{dez} / 12$ & MT & $\begin{array}{l}\text { Centro } \\
\text { Oeste }\end{array}$ \\
\hline $\begin{array}{c}\text { Formação de Docentes em Química e Ensino } \\
\text { na Região do Sertão do Araripe, PE }\end{array}$ & IF Sertão PE & ago/13 & PE & Nordeste \\
\hline $\begin{array}{l}\text { Ensino de Química: Novas Metodologias } \\
\text { aplicadas ao Ensino, Educação Ambientalm, } \\
\text { Desenvolvimento de Programas e Softwares }\end{array}$ & IF Sertão PE & $\mathrm{abr} / 13$ & $\mathrm{PE}$ & Nordeste \\
\hline
\end{tabular}




\begin{tabular}{|c|c|c|c|c|}
\hline $\begin{array}{l}\text { voltados ao Ensino de Qupimica, Didática e } \\
\text { Psicologia Aplicada. }\end{array}$ & & & & \\
\hline $\begin{array}{c}\text { Materiais para o ensino de Química: técnico e } \\
\text { superior. }\end{array}$ & IFB & out/12 & DF & $\begin{array}{l}\text { Centro } \\
\text { Oeste }\end{array}$ \\
\hline $\begin{array}{l}\text { Desenvolvimento de ferramentas } \\
\text { educacionais para o ensino }\end{array}$ & IFBA & mai/13 & BA & Nordeste \\
\hline Ensino de química & IFMA & mai/12 & MA & Nordeste \\
\hline Química & IFMA & mai/13 & MA & Nordeste \\
\hline Educação Química & IFMA & mai/13 & MA & Nordeste \\
\hline CTS e Ensino de Química & IFMA & mai/13 & MA & Nordeste \\
\hline $\begin{array}{l}\text { Desenvolvimento de Jogos e Atividades } \\
\text { Lúdicas Aplicados ao Ensino de Química }\end{array}$ & IFMA & mai/13 & MA & Nordeste \\
\hline $\begin{array}{l}\text { Desenvolvimento de Materiais Alternativos } \\
\text { para o Ensino de Química }\end{array}$ & IFMA & mai/13 & MA & Nordeste \\
\hline Formação de Professores de Química & IFMA & mai/13 & MA & Nordeste \\
\hline $\begin{array}{c}\text { Interdisciplinaridade e transdisciplinaridade } \\
\text { no ensino de química e ciências }\end{array}$ & IFMA & mai/13 & MA & Nordeste \\
\hline Educação em Química & IFMA & jun/13 & MA & Nordeste \\
\hline Ensino de Química & IFMA & jun/13 & MA & Nordeste \\
\hline Educação Ambiental e Ensino de Ciências & IFMA & ago/13 & MA & Nordeste \\
\hline Ensino de Química & IFPB & ago/12 & PB & Nordeste \\
\hline Ensino de Química para Petroquímica & IFPB & ago/12 & PB & Nordeste \\
\hline $\begin{array}{c}\text { Desenvolvimento de Metodologias } \\
\text { Alternativas no Ensino de Química com } \\
\text { Inclusão de Alunos Surdos e Ouvintes, com } \\
\text { ênfase na modalidade EJA/PROEJA }\end{array}$ & IFPB & $\mathrm{jul} / 13$ & PB & Nordeste \\
\hline Educação em Química & IFPB & ago/13 & PB & Nordeste \\
\hline Ensino de Ciências & IFRJ & ago/13 & RJ & Sudeste \\
\hline Ensino de Química & IFRJ & $\mathrm{abr} / 13$ & RJ & Sudeste \\
\hline Educação em Química; & IFRN & fev/12 & $\mathrm{RN}$ & Nordeste \\
\hline Ensino de Química; & IFRN & $\mathrm{fev} / 12$ & $\mathrm{RN}$ & Nordeste \\
\hline $\begin{array}{l}\text { Estudo de procedimentos didáticos } \\
\text { metodológicos para o ensino da Química }\end{array}$ & IFRN & $\mathrm{jul} / 13$ & $\mathrm{RN}$ & Nordeste \\
\hline Educação e Meio Ambiente & IFRS & ago/13 & RS & Sul \\
\hline Ensino da Química & IFSEMG & fev/13 & MG & Sudeste \\
\hline $\begin{array}{c}\text { Objetos de Aprendizagem em òlímeros e } \\
\text { Química }\end{array}$ & IFSUL & jun/12 & RS & Sul \\
\hline $\begin{array}{c}\text { Material Hipermídia ao Ensino Superior na } \\
\text { área de Química }\end{array}$ & PUC/PR & $\mathrm{dez} / 10$ & PR & Sul \\
\hline Química em Sistemas do Cotidiano & PUC/PR & $\mathrm{dez} / 10$ & PR & Sul \\
\hline $\begin{array}{c}\text { Educação Ambiental em Espaço Escolares: } \\
\text { Ensino de Química e Formação de Professores }\end{array}$ & UCB/DF & mai/13 & DF & $\begin{array}{l}\text { Centro } \\
\text { Oeste }\end{array}$ \\
\hline $\begin{array}{c}\text { Educação Ambiental em Espaço Escolares: } \\
\text { Ensino de Química e Formação de Professores }\end{array}$ & UCB/DF & mai/13 & $\mathrm{DF}$ & $\begin{array}{l}\text { Centro } \\
\text { Oeste }\end{array}$ \\
\hline Ensino de Química no Nível Médio & UECE & ago/13 & CE & Nordeste \\
\hline Formação de Professores de Química & UECE & ago/13 & CE & Nordeste \\
\hline Livros Paradidáticos na Área de Química & UECE & ago/13 & CE & Nordeste \\
\hline Manual de Química do Dia-a-Dia & UECE & ago/13 & CE & Nordeste \\
\hline
\end{tabular}




\begin{tabular}{|c|c|c|c|c|}
\hline Pesquisa Educacional em Química & UECE & ago/13 & CE & Nordeste \\
\hline Produção de Monografias & UECE & ago/13 & CE & Nordeste \\
\hline Ensino de Ciências: Química e Biologia & UECE & $a b r / 13$ & CE & Nordeste \\
\hline Métodos alternativos para estudo da química & UEMA & $a b r / 13$ & MA & Nordeste \\
\hline Atividades Lúdicas no Ensino de Química & UEMS & $\mathrm{mar} / 12$ & MS & $\begin{array}{l}\text { Centro } \\
\text { Oeste }\end{array}$ \\
\hline Modelagem Molecular no Ensino de Ciências & UEPA & ago/13 & PA & Norte \\
\hline Educação e Química Ambiental & UEPG & $\mathrm{mar} / 13$ & PR & Sul \\
\hline Pesquisa em Educação Química & UERJ & $\mathrm{dez} / 10$ & RJ & Sudeste \\
\hline Educação Química e Divulgação Científica & UESB & mai/13 & BA & Nordeste \\
\hline Experimentação em Química e Física & UESB & mai/13 & $\mathrm{BA}$ & Nordeste \\
\hline A experimentação no ensino de química & UESC & set/11 & BA & Nordeste \\
\hline Argumentação no Ensino de Química & UESC & set/11 & BA & Nordeste \\
\hline $\begin{array}{l}\text { Conteúdos curriculares e seus impactos na } \\
\text { sala de aula }\end{array}$ & UESC & set/11 & BA & Nordeste \\
\hline $\begin{array}{c}\text { Construção de unidades didáticas e análise do } \\
\text { processo de transferência em diferentes } \\
\text { contextos }\end{array}$ & UESC & set/11 & BA & Nordeste \\
\hline $\begin{array}{l}\text { Formação inicial e continuada de professores } \\
\text { de química }\end{array}$ & UESC & set/11 & BA & Nordeste \\
\hline Metodologia do Ensino de Química & UFAL & ago/12 & $A L$ & Nordeste \\
\hline $\begin{array}{l}\text { Instrumentação para o ensino de Química de } \\
\text { Produtos Naturais }\end{array}$ & UFAM & jun/13 & AM & Norte \\
\hline $\begin{array}{c}\text { Ensino e aprendizagem de conceitos } \\
\text { científicos }\end{array}$ & UFAM & $\mathrm{jul} / 13$ & AM & Norte \\
\hline Educação, Química e Sociedade & UFAM & dez/12 & AM & Norte \\
\hline $\begin{array}{c}\text { Experimentação e Produção de Material } \\
\text { Didático para o Ensino da Química }\end{array}$ & UFAP & $\mathrm{jan} / 13$ & AP & Norte \\
\hline $\begin{array}{l}\text { Formação Inicial e Continuada de Professores } \\
\text { de Química }\end{array}$ & UFAP & jan/13 & AP & Norte \\
\hline $\begin{array}{c}\text { Prática de Ensino e, Química: Atuação } \\
\text { Consciente da Realidade Atual e Regional. }\end{array}$ & UFC & $\mathrm{dez} / 10$ & CE & Nordeste \\
\hline Ensino de Química e Ciências da Natureza & UFES & $\mathrm{mar} / 13$ & ES & Sudeste \\
\hline $\begin{array}{c}\text { Simulação Computacional Aplicada ao } \\
\text { Currículo do Ensino Superior de Química } \\
\text { Orgânica }\end{array}$ & UFES & set/12 & ES & Sudeste \\
\hline $\begin{array}{l}\text { Aplicação de Software livre para o ensino de } \\
\text { Química }\end{array}$ & UFES & fev/13 & ES & Sudeste \\
\hline $\begin{array}{l}\text { Desenvolvimento e aplicação de jogos } \\
\text { didáticos no ensino de química. }\end{array}$ & UFES & fev/13 & ES & Sudeste \\
\hline $\begin{array}{l}\text { Desenvolvimento e aplicação de metodologias } \\
\text { alternativas no ensino de Química no norte do } \\
\text { Espírito Santo }\end{array}$ & UFES & fev/13 & ES & Sudeste \\
\hline Ensino de Química & UFF & $\mathrm{dez} / 12$ & RJ & Sudeste \\
\hline Química Ensino-Aprendizagem & UFG & jun/12 & GO & $\begin{array}{l}\text { Centro } \\
\text { Oeste }\end{array}$ \\
\hline Robótica Educacional e Ensino de Ciências & UFG & jun/13 & GO & $\begin{array}{l}\text { Centro } \\
\text { Oeste }\end{array}$ \\
\hline $\begin{array}{l}\text { Jogos e Atividades Lúdicas em Ensino de } \\
\text { Ciências }\end{array}$ & UFG & jun/13 & GO & $\begin{array}{l}\text { Centro } \\
\text { Oeste }\end{array}$ \\
\hline
\end{tabular}




\begin{tabular}{|c|c|c|c|c|}
\hline $\begin{array}{c}\text { Educação e Formação Profissional (Médio e } \\
\text { Superior) }\end{array}$ & UFG & jun/13 & GO & $\begin{array}{l}\text { Centro } \\
\text { Oeste }\end{array}$ \\
\hline $\begin{array}{l}\text { O início da carreira docente: reflexões e } \\
\text { possibilidades }\end{array}$ & UFMT & mai/13 & MT & $\begin{array}{l}\text { Centro } \\
\text { Oeste }\end{array}$ \\
\hline $\begin{array}{c}\text { Saberes docentes e a elaboração de Material } \\
\text { Didático }\end{array}$ & UFMT & mai/13 & MT & $\begin{array}{l}\text { Centro } \\
\text { Oeste }\end{array}$ \\
\hline Ensino de Química & UFPA & jun/12 & PA & Norte \\
\hline Pesquisa em ensino de química & UFPA & fev/13 & PA & Norte \\
\hline $\begin{array}{c}\text { Pernambuco, imortal, imortal! A História de } \\
\text { Pernambuco como tema gerador no ensino de } \\
\text { Química }\end{array}$ & UFPE & $a b r / 13$ & PE & Nordeste \\
\hline Ensino de Química & UFPI & ago/13 & $\mathrm{PI}$ & Nordeste \\
\hline Ensino de Química & UFPI & $\mathrm{fev} / 13$ & $\mathrm{PI}$ & Nordeste \\
\hline Ensino de Ciências e Tecnologia & UFRB & mai/13 & BA & Nordeste \\
\hline $\begin{array}{l}\text { Análise linguístico-terminológica de livros } \\
\text { didáticos de química do nível superior }\end{array}$ & UFRGS & ago/12 & RS & Sul \\
\hline Epistemologia da química & UFRGS & ago/12 & RS & Sul \\
\hline Estudos sobre Currículo e Saberes & UFRGS & ago/12 & RS & Sul \\
\hline $\begin{array}{l}\text { Modelagem e implementação de ambientes } \\
\text { de aprendizagem com o uso do computador }\end{array}$ & UFRGS & ago/12 & RS & Sul \\
\hline $\begin{array}{c}\text { Os Discursos e a Gestão das Disciplinas e seus } \\
\text { Conteúdos }\end{array}$ & UFRGS & ago/12 & RS & Sul \\
\hline $\begin{array}{l}\text { Práticas Investigativas na Formação de } \\
\text { Professores }\end{array}$ & UFRGS & ago/12 & RS & Sul \\
\hline Ensino de Química & UFRN & $\mathrm{jul} / 13$ & RN & Nordeste \\
\hline Popularização da Química & UFRPE & mar/13 & $\mathrm{PE}$ & Nordeste \\
\hline Ensino de Química & UFRPE & mar/13 & PE & Nordeste \\
\hline $\begin{array}{c}\text { Educação Química e Sustentabilidade } \\
\text { Ambiental }\end{array}$ & UFSC & jun/13 & SC & Sul \\
\hline Ensino de Química e formação de professores & UFSC & $\mathrm{jul} / 13$ & SC & Sul \\
\hline Experimentação no Ensino de Química & UFSC & ago/13 & $\mathrm{SC}$ & Sul \\
\hline $\begin{array}{l}\text { O ensino da química na perspectiva } \\
\text { Agroecológica e do saneamento ambiental }\end{array}$ & UFSC & set/13 & SC & Sul \\
\hline $\begin{array}{c}\text { representações conceituais e modelos } \\
\text { mentais }\end{array}$ & UFSC & out/13 & SC & Sul \\
\hline Metodologias para o ensino de Química & UFSM & $\mathrm{jul} / 12$ & RS & Sul \\
\hline $\begin{array}{c}\text { Educação Científica: Processos de Ensino e } \\
\text { Aprendizagem na Escola, na Universidade e } \\
\text { no Laboratório de Pesquisa }\end{array}$ & UFSM & $\mathrm{jul} / 12$ & RS & Sul \\
\hline Ensino de Modelagem Molecular & UFSM & mar/12 & RS & Sul \\
\hline Ensino de Química & UFTM & out/12 & MG & Sudeste \\
\hline $\begin{array}{c}\text { Desenvolvimento de Tecnologia e Recursos } \\
\text { Didático-Pedagógicos para Química }\end{array}$ & UFV & mar/13 & MG & Sudeste \\
\hline $\begin{array}{c}\text { Desenvolvimento de Estratégias de Ensino em } \\
\text { Química }\end{array}$ & UFVASF & mai/13 & $\mathrm{PE}$ & Nordeste \\
\hline Educação Química & UNEB & nov/11 & BA & Nordeste \\
\hline Educação e Ensino de Química & Uniararas & $\mathrm{abr} / 13$ & SP & Sudeste \\
\hline $\begin{array}{l}\text { Ensino de Química - A Produção e Utilização } \\
\text { de Crônicas e Vídeos no Ensino de Química. }\end{array}$ & UNICAMP & mai/13 & SP & Sudeste \\
\hline
\end{tabular}




\begin{tabular}{|c|c|c|c|c|}
\hline $\begin{array}{l}\text { Ensino de Química - Desenvolvimento de } \\
\text { Experimentos para o Ensino Médio e Superior }\end{array}$ & UNICAMP & mai/13 & SP & Sudeste \\
\hline $\begin{array}{c}\text { Ensino de Química - Desenvolvimento e } \\
\text { Utilização de Animações no Ensino de } \\
\text { Química }\end{array}$ & UNICAMP & mai/13 & SP & Sudeste \\
\hline $\begin{array}{l}\text { Ensino de Química - Diferentes Abordagens } \\
\text { para Conceitos Básicos de Química, do Ensino } \\
\text { Médio ao Superior. }\end{array}$ & UNICAMP & mai/13 & SP & Sudeste \\
\hline $\begin{array}{l}\text { Ensino de Química - Preparação de Material } \\
\text { Didático para Abordagens Não Presenciais }\end{array}$ & UNICAMP & mai/13 & SP & Sudeste \\
\hline $\begin{array}{c}\text { Ensino de Química - Preparação de Material } \\
\text { Didático para o Nível Superior }\end{array}$ & UNICAMP & mai/13 & SP & Sudeste \\
\hline Ensino de Química & UNICAMP & mai/13 & SP & Sudeste \\
\hline Química Analítica e Ensino & UNICAMP & mai/13 & SP & Sudeste \\
\hline Ensino & UNICAMP & mai/13 & SP & Sudeste \\
\hline Ensino de Química Experimental & UNICENTRO & fev/13 & PR & Sul \\
\hline Ensino de Modelagem Molecular & UNIFAP & set/13 & AP & Norte \\
\hline $\begin{array}{c}\text { Ensino de Química e Educação Sócio } \\
\text { Ambiental a partir da abordagem CTSA }\end{array}$ & UNIFESP & mai/12 & SP & Sudeste \\
\hline $\begin{array}{c}\text { História do Ensino de Química: a apropriação } \\
\text { do conhecimento químico em diferentes } \\
\text { contextos }\end{array}$ & UNIFESP & mai/12 & SP & Sudeste \\
\hline Ensino em química e ciência & UNIFRAN & jun/13 & SP & Sudeste \\
\hline Química Sustentável & UNIGRANRIO & jun/13 & RJ & Sudeste \\
\hline $\begin{array}{c}\text { Desenvolvimento e adaptação tecnológica em } \\
\text { Química }\end{array}$ & UNIOESTE & ago/13 & PR & Sul \\
\hline $\begin{array}{l}\text { Educação em Química: fundamentos teóricos } \\
\text { e epistemológicos das Ciências Naturais e sua } \\
\text { relação com a educação escolar }\end{array}$ & UNIOESTE & ago/13 & PR & Sul \\
\hline $\begin{array}{c}\text { Estudos sobre o ensino de Química na } \\
\text { Universidade e na Escola }\end{array}$ & UNIOESTE & ago/13 & PR & Sul \\
\hline Saberes Populares & URI & mai/13 & RS & Sul \\
\hline Ensino de Química & USP & jan/12 & SP & Sudeste \\
\hline $\begin{array}{l}\text { Estado da arte da pesquisa em ensino de } \\
\text { ciências }\end{array}$ & USP & $\mathrm{jul} / 13$ & SP & Sudeste \\
\hline Formação de professores & USP & $\mathrm{jul} / 13$ & SP & Sudeste \\
\hline Metodologia de ensino & USP & jul/13 & SP & Sudeste \\
\hline Ensino e Aprendizagem de Química & USP & nov/11 & SP & Sudeste \\
\hline Formação inicial e continuada de Professores & USP & nov/11 & SP & Sudeste \\
\hline Artes Cênicas no Ensino e Difusão da Química & USP & out/12 & SP & Sudeste \\
\hline $\begin{array}{c}\text { Desenvolvimento de Experimentos para o } \\
\text { Ensino de Química Analítica }\end{array}$ & USP & mar/12 & SP & Sudeste \\
\hline $\begin{array}{c}\text { Desenvolvimento de praticas experimentais } \\
\text { para o ensino básico }\end{array}$ & UTFPR & jun/11 & PR & Sul \\
\hline Experimentação no ensino de química & UTFPR & ago/13 & PR & Sul \\
\hline $\begin{array}{l}\text { Formação continuada de professores de } \\
\text { química }\end{array}$ & UTFPR & ago/13 & PR & Sul \\
\hline Ensino de Química & UTFPR & $a b r / 13$ & PR & Sul \\
\hline $\begin{array}{c}\text { Elaboração de Jogos Alternativos para Ensino } \\
\text { e Divulgação da Química }\end{array}$ & UTFPR & mai/11 & PR & Sul \\
\hline
\end{tabular}




\begin{tabular}{|c|c|c|c|c|}
\hline $\begin{array}{c}\text { Elaboração de Material Paradidático para } \\
\text { Ensino e Divulgação da Química }\end{array}$ & UTFPR & mai/11 & PR & Sul \\
\hline
\end{tabular}

Anexo 2 - Linhas de pesquisa em “Linguagem e formação de Conceitos” atualizados entre 2010 e 2013 no site do CNPq.

\begin{tabular}{|c|c|c|c|c|}
\hline Linha de Pesquisa & IES & $\begin{array}{c}\text { Última } \\
\text { Atualização }\end{array}$ & UF & Região \\
\hline $\begin{array}{l}\text { Ensino e aprendizagem de conceitos } \\
\text { científicos }\end{array}$ & UFAM & $\mathrm{jul} / 13$ & AM & Norte \\
\hline A experimentação no ensino de química & UESC & set/11 & BA & Nordeste \\
\hline Argumentação no Ensino de Química & UESC & set/11 & BA & Nordeste \\
\hline $\begin{array}{c}\text { Construção de unidades didáticas e análise do } \\
\text { processo de transferência em diferentes } \\
\text { contextos }\end{array}$ & UESC & set/11 & BA & Nordeste \\
\hline Livros Paradidáticos na Área de Química & UECE & ago/13 & CE & Nordeste \\
\hline $\begin{array}{c}\text { Simulação Computacional Aplicada ao } \\
\text { Currículo do Ensino Superior de Química } \\
\text { Orgânica }\end{array}$ & UFES & set/12 & ES & Sudeste \\
\hline Robótica Educacional e Ensino de Ciências & UFG & jun/13 & GO & $\begin{array}{l}\text { Centro } \\
\text { Oeste }\end{array}$ \\
\hline $\begin{array}{l}\text { Pernambuco, imortal, imortal! A História de } \\
\text { Pernambuco como tema gerador no ensino de } \\
\text { Química }\end{array}$ & UFPE & $a b r / 13$ & $\mathrm{PE}$ & Nordeste \\
\hline $\begin{array}{l}\text { Análise linguístico-terminológica de livros } \\
\text { didáticos de química do nível superior }\end{array}$ & UFRGS & ago/12 & RS & Sul \\
\hline Epistemologia da química & UFRGS & ago/12 & RS & Sul \\
\hline Saberes Populares & URI & mai/13 & RS & Sul \\
\hline $\begin{array}{c}\text { representações conceituais e modelos } \\
\text { mentais }\end{array}$ & UFSC & out/13 & SC & Sul \\
\hline Educação e Ensino de Química & Uniararas & $\mathrm{abr} / 13$ & SP & Sudeste \\
\hline $\begin{array}{l}\text { Ensino de Química - A Produção e Utilização } \\
\text { de Crônicas e Vídeos no Ensino de Química. }\end{array}$ & UNICAMP & mai/13 & SP & Sudeste \\
\hline $\begin{array}{l}\text { Ensino de Química - Diferentes Abordagens } \\
\text { para Conceitos Básicos de Química, do Ensino } \\
\text { Médio ao Superior. }\end{array}$ & UNICAMP & mai/13 & SP & Sudeste \\
\hline Ensino e Aprendizagem de Química & USP & nov/11 & SP & Sudeste \\
\hline
\end{tabular}

